\title{
A tree-ring-based reconstruction of the Yimin River annual runoff in the Hulun Buir region, Inner Mongolia, for the past 135 years
}

\author{
BAO Guang ${ }^{1,2}$, LIU Yu ${ }^{2,3^{*}} \& \mathrm{LIU} \mathrm{Na}^{1}$ \\ ${ }^{1}$ Key Laboratory of Disaster Monitoring and Mechanism Simulating of Shaanxi Province, Baoji University of Arts and Sciences, \\ Baoji 721013, China; \\ ${ }^{2}$ The State Key Laboratory of Loess and Quaternary Geology, Institute of Earth Environment, Chinese Academy of Sciences, \\ Xi'an 710075, China; \\ ${ }^{3}$ Department of Environmental Science and Technology, School of Human Settlements and Civil Engineering, Xi'an Jiaotong University, \\ Xi'an 710049, China
}

Received June 25, 2012; accepted October 8, 2012

\begin{abstract}
Based on the relationships between the regional tree-ring chronology (RC) of moisture-sensitive Pinus sylvestris var. mongolica and the monthly mean maximum temperature, annual precipitation and annual runoff, a reconstruction of the runoff of the Yimin River was performed for the period 1868-2002. The model was stable and could explain 52.2\% of the variance for the calibration period of 1956-2002. During the past 135 years, 21 extremely dry years and 19 extremely wet years occurred. These years represented $15.6 \%$ and $14.1 \%$ of the total study period, respectively. Six severe drought events lasting two years or more occurred in 1950-1951, 1986-1987, 1905-1909, 1926-1928, 1968-1969 and 1919-1920. Four wetter events occurred during 1954-1959, 1932-1934, 1939-1940 and 1990-1991. Comparisons with other tree-ring-based streamflow reconstructions or chronologies for surrounding areas supplied a high degree of confidence in our reconstruction. Power spectrum and wavelet analyses suggested that the reconstructed annual runoff variation in the Hulun Buir region and surrounding area could be associated with large-scale atmospheric-oceanic variability, such as the Pacific Decadal Oscillation (PDO) and El Niño-Southern Oscillation (ENSO), and sunspot activity.
\end{abstract}

tree ring, Hulun Buir, Yimin River, annual runoff, reconstruction

Citation: Bao G, Liu Y, Liu N. A tree-ring-based reconstruction of the Yimin River annual runoff in the Hulun Buir region, Inner Mongolia, for the past 135 years. Chin Sci Bull, 2012, 57: 4765-4775, doi: 10.1007/s11434-012-5547-7

Most parts of China have suffered from severe and prolonged droughts in recent years [1], particularly the extreme four-year drought extending from 1999 to 2002. These droughts have caused large economic and societal losses [2]. For instance, the severe drought of 2000 in Inner Mongolia resulted in the loss of $80 \times 10^{4}$ ha of crops, $14 \%$ of the total crop area (http://www.weather.com.cn/zt/kpzt/1244063. shtml). The 2001 drought also influenced $60 \times 10^{4}$ ha of planting area and caused great damage to the yield from $297 \times 10^{4}$ ha and $5733 \times 10^{4}$ ha of crops and pasture, respectively (http://www.weather.com.cn/zt/kpzt/1244064.shtml). Such droughts have severe impacts on agricultural produc-

\footnotetext{
*Corresponding author (email: liuyu@ @loess.llqg.ac.cn)
}

tion, and the frequency and severity of droughts and hydroclimatic events are also of critical importance in water resource management.

Because the required hydrological data have only been obtained using recording instruments since the 1950s, long-term hydrological reconstructions based on tree-ring studies are very valuable for the management and planning of water resources $[3,4]$. The statistical relationship between tree-ring index data and the hydroclimatic records of variables such as runoff and streamflow has been exploited to construct reconstructions that are hundreds of years in length for many parts of the world [5-10].

Pinus sylvestris var. mongolica is one of the major coniferous tree species of the boreal forests in China, and is 
native to the Hulun Buir region and northern Da Hinggan Mountains. In recent years, several dendroclimatological studies have been conducted in these regions using tree-ring material from this pine species. Based on analyses of the tree-ring width index and the normalized difference vegetation index (NDVI), He et al. [11] found that the monthly and annual NDVI changes in Mohe, located in northern China, are driven by temperature. Based on the relationships between tree-ring density and width and climatic factors, Wang et al. [12] found that the latewood density of Pinus sylvestris var. mongolica is controlled by the maximum temperature in July and August, as well as by the length of the growing season. The climate-growth responses from four sites in the northern Da Hinggan Mountains have been studied by Wang et al. [13], who concluded that temperature is the major limiting factor for tree growth. A 292year-long mean temperature reconstruction has also been developed for that region by Zhang et al. [14]. In the Hulun Buir region, the annual precipitation $[15,16]$ and seasonal temperature [17] were reconstructed using robust tree-ring width chronologies of Pinus sylvestris var. mongolica. However, the previous studies cited above primarily investigated the relationships between tree growth and temperature, as well as precipitation. However, no dendrohydrological studies have been reported.

The purposes of this study were to reconstruct the annual runoff of the Yimin River from 1868 to 2002 for the Hulun Buir region, Inner Mongolia, and to explore the linkage between the hydroclimatic variations reflected by the runoff reconstruction and large-scale climate forcing.

\section{Materials and methods}

\subsection{Study area and climate}

The Yimin River originates from the northern slope of
Mushroom Mountain in the western part of the Da Hinggan Mountains and the south central part of the Hulun Buir Grassland. The river flows from south to north through the entire Ewenke Banner and Hailar District and then runs into the Hailar River. The Yimin River has a length of $360 \mathrm{~km}$ and a drainage area of $22647 \mathrm{~km}^{2}$ [18] (Figure 1). As shown in Figure 2, which illustrates the distribution of temperature and precipitation at the Hailar and Aershan meteorological stations (Table 1), the climate displays typical monsoon characteristics with mild, wet summers and cold, dry winters [19]. Seasonal dry and wet conditions alternate in association with the intrusion of dry, cold air masses from high latitudes in winter and warm, humid air masses from low-latitude oceans in summer [20]. The averaged data for the Hailar and Aershan stations show an annual mean temperature of $-1.99^{\circ} \mathrm{C}$, a mean maximum temperature of $4.94^{\circ} \mathrm{C}$ and an annual total precipitation of $399 \mathrm{~mm}$ for



Figure 1 Location of the sampling sites, meteorological stations and hydrological stations.

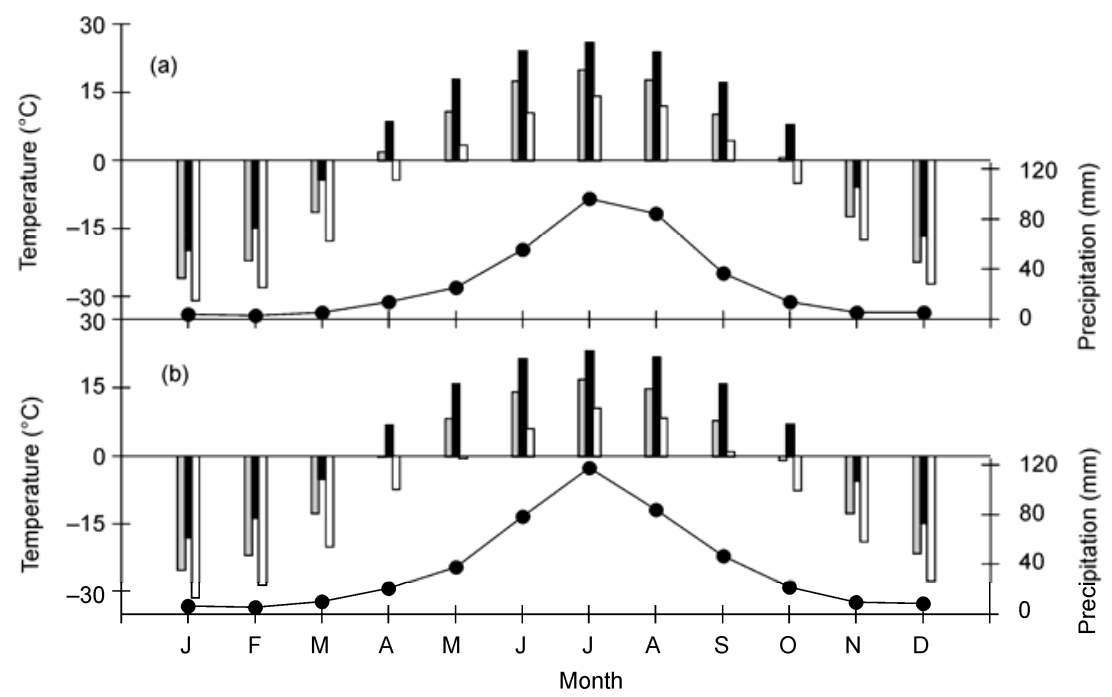

Figure 2 Monthly mean temperature (grey bar), mean maximum temperature (black bar), mean minimum temperature (white bar) and monthly precipitation for the (a) Hailar and (b) Aershan meteorological stations (1953-2008). 
Table 1 Information on the sampling sites (tree-ring chronology) and associated meteorological stations

\begin{tabular}{|c|c|c|c|c|}
\hline Site code & HLBEstd & NGNEstd & Hailar & Aershan \\
\hline Longitude (E) & $119^{\circ} 43^{\prime}$ & $119^{\circ} 22.037^{\prime}-119^{\circ} 23.788^{\prime}$ & $119^{\circ} 45^{\prime}$ & $119^{\circ} 57^{\prime}$ \\
\hline Latitude $(\mathrm{N})$ & $47^{\circ} 12^{\prime}$ & $47^{\circ} 59.539^{\prime}-47^{\circ} 59.851^{\prime}$ & $49^{\circ} 13^{\prime}$ & $47^{\circ} 10^{\prime}$ \\
\hline Elevation (m) & $450-600$ & $760-790$ & 610 & 1027 \\
\hline Sample depth (core/tree) & $40 / 23$ & $67 / 35$ & & \\
\hline Mean sensitivity (MS) & 0.23 & 0.19 & & \\
\hline Expressed population signal (EPS) & 0.91 & 0.96 & & \\
\hline First year where $\mathrm{SSS}>0.75$ (number of trees) & $1865(8)$ & $1868(5)$ & & \\
\hline First year where $S S S>0.80$ (number of trees) & $1868(10)$ & $1869(6)$ & & \\
\hline Time span & $1865-2003$ & $1868-2009$ & 1951-2008 & $1953-2008$ \\
\hline
\end{tabular}

1953-2008 (Table 1). Averaging meteorological records from more stations could decrease the small-scale noise or stochastic components and represent the broader regional climatic conditions. Therefore, we used the averaged data set of the Hailar and Aershan stations for further analysis.

\subsection{Tree-ring data}

Tree-ring samples were collected from two pure stands of Pinus sylvestris var. mongolica forest (Figure 1, Table 1). One site is at Nuogannuoer (NGNE) [17], located in the southwestern part of the upper section of the Yimin River, and the other site is at West Mountain in the Hailar District (HLBE) [15], on a downstream section of the river. Most trees grow on sand dunes in poor soil, and each pine stand is quite open, with a discontinuous canopy. Descriptions of these two sites and the tree-ring chronologies developed for each site were presented previously $[15,17]$. Two tree-ring width standard chronologies were utilized in this study, namely NGNEstd [17] and HLBEstd [15]. The mean sensitivity (MS), a measure of the relative difference in widths between adjacent rings, was 0.19 and 0.23 , respectively, for the NGNEstd and HLBEstd chronologies. The expressed population signal (EPS), which represents an acceptable level of confidence in a chronology, was 0.96 and 0.91 , respectively, for the NGNEstd and HLBEstd chronologies, which are greater than the threshold value of 0.85 [21]. These statistical values indicated that the two chronologies provided a robust signal strength suitable for investigating climate variations. The subsample signal strength (SSS) was determined to assess the adequacy of replication in the early years of the tree-ring chronologies [21]. To use the maximum length of the chronologies and ensure the reliability of the reconstructions, we restricted our analysis to a period with an SSS value of at least 0.75 . The effective spans determined by this threshold are 1865-2003 for HLBEstd and 1868-2009 for NGNEstd (Table 1).

The significant correlation between NGNEstd and HLBEstd $(r=0.541, n=136, P<0.0001)$ and the first principal component explained $77 \%$ of the total variance. Moreover, growth conditions were similar at the two sites. For these reasons, a regional chronology (RC) was developed by averaging the two chronologies over their reliable common time period, 1868-2003. The sample depth for 1868, the initial year, was 17 cores/15 trees (Figure 3).

The annual runoff data for 1956-2006 from the Hailar and Huihekou hydrological stations were used in this study [18] (Figure 1). The two hydrological records were significantly correlated $(r=0.896, n=51, P<0.0001)$, and the first principal component explained $94.8 \%$ of the total variance. Accordingly, a regional annual runoff dataset for the Yimin River was developed by averaging the annual runoff series from the Hailar and Huihekou stations.

A correlation function analysis was performed to investigate the relationship between the tree-ring width indices, monthly mean precipitation and mean maximum temperature from the previous June to the current October and the regional annual runoff of the Yimin River during the observation period for the three chronologies. Power spectrum and wavelet analyses [22] were applied to explore the teleconnections between regional hydroclimatic variations reflected by the tree-ring reconstructions in our study area and vicinity and large-scale climate forcing.

\section{Results and discussion}

\subsection{Climate-growth response}

As shown in Figure 4, precipitation was significantly positively correlated with HLBEstd, NGNEstd and RC, whereas temperature was negatively correlated with the three chronologies except for the previous October, November and December. In the current growth year, for example, the correlation coefficients between $\mathrm{RC}$ and the sum of seasonal precipitation from April to October and between RC and the mean maximum temperature (April-October) were 0.358 $(P=0.01)$ and $-0.452(P=0.001)$, respectively. Moreover, both precipitation (August and September) and the maximum temperature (June, July, August and September) in the previous year strongly influenced tree growth in the current 

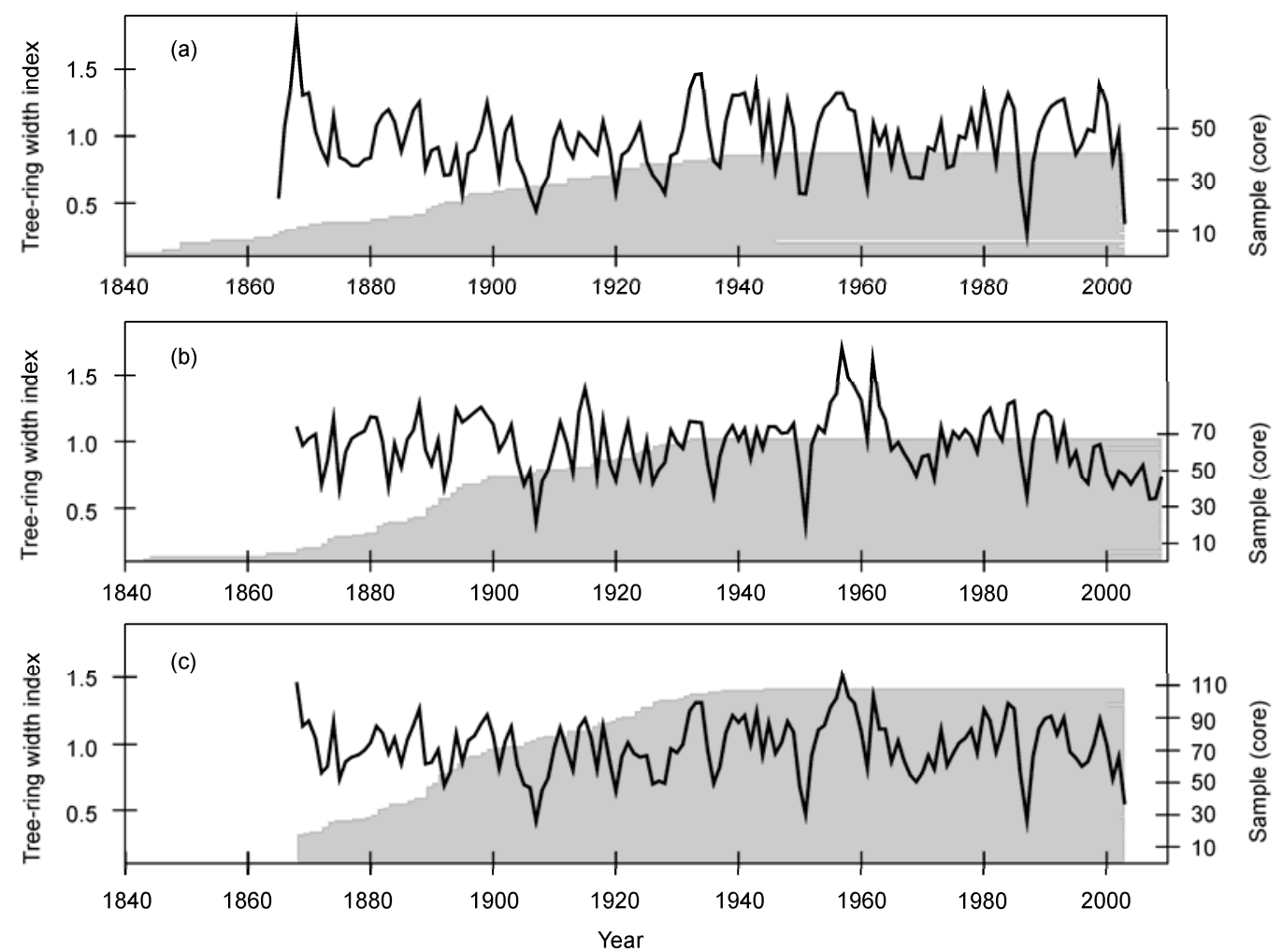

Figure 3 Chronology and sample depth for HLBEstd (a), NGNEstd (b) and RC (c).

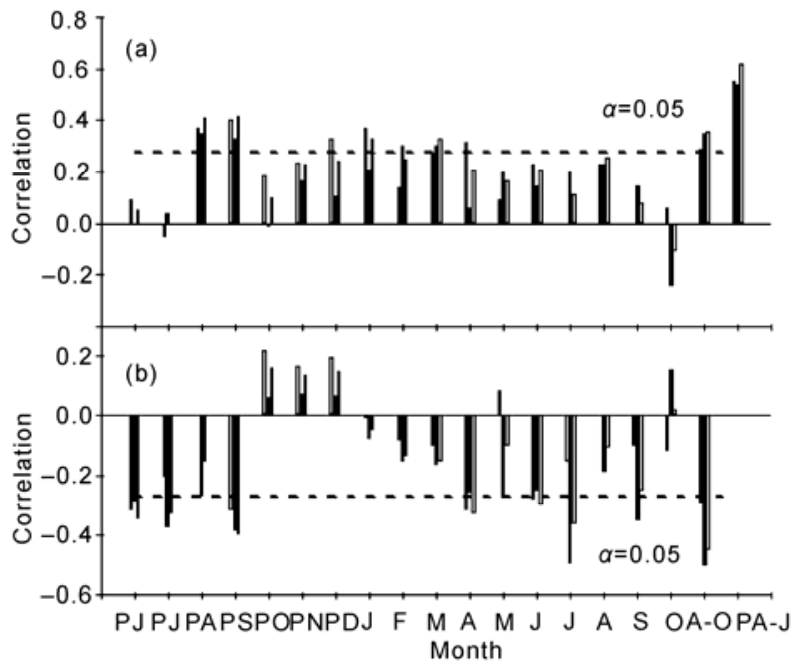

Figure 4 Correlations between tree-ring chronology (HLBEstd (grey bar), NGNEstd (black bar) and RC (white bar)) and the (a) monthly sum of precipitation and (b) mean maximum temperature. In this figure, $\mathrm{P}$ means previous year; A-O refers to the current April to October; PA-J refers to the previous August to the current July; and the dotted line indicates the 0.05 significance level.

year. In particular, significant correlations of 0.554 $(P<0.0001), 0.542(P<0.0001)$ and $0.619(P<0.0001)$ were found between the total precipitation from the previous August to the current July and HLBEstd, NGNEstd and RC, respectively.

In general, tree growth in and near semi-arid regions is primarily determined by the effective precipitation. Temperature (maximum temperature) affects the growth of trees by influencing the amount of moisture in the soil, as well as the respiration and transpiration rate of trees, especially if precipitation is not adequate during the growing season $[6,23,24]$. This pattern can often be inferred from tree-ring width chronologies that are positively correlated with rainfall and negatively correlated with temperature [25,26].

Compared with single climatic factors, runoff could integrate many factors, such as precipitation, temperature and evaporation, by which regional climatic features are represented [27]. Similar responses are shown by the relationship between the annual runoff of the Yimin River and maximum temperature and seasonal/annual precipitation, as well as by the relationship between the regional tree-ring width chronology and these climatic factors (Table 2). For instance, the correlation coefficients associated with the April-September mean maximum temperature $\left(T_{4-9(\max )}\right)$, the seasonal precipitation for April-September $\left(P_{4-9}\right)$ and the annual precipitation from the previous August to the current July $\left(P_{8-7}\right)$ were $-0.406,0.64$ and 0.669 , respectively, for the annual runoff of the Yimin River and $-0.465,0.381$ and 0.619 , respectively, for the RC. The similar correlation coefficients associated with $P_{4-9}(0.64)$ and calendar-year annual precipitation $\left(P_{\mathrm{ann}}\right)(0.674)$ for the annual runoff of the Yimin River indicated that the Yimin River annual runoff was dominated by the summer rainfall (one-half of the year) [28]. The synchronous variations in the annual runoff of the 
Table 2 Correlations of the RC and mean annual runoff of the Yimin River with the temperature and precipitation ${ }^{\text {a) }}$

\begin{tabular}{ccccc}
\hline & $T_{4-9(\max )}(P, n)$ & $P_{4-9}$ & $P_{8-7}$ & $P_{\text {ann }}$ \\
\hline RC & $-0.465(0.001,51)$ & $0.381(0.006,51)$ & $0.619(0.0001,50)$ & $0.383(0.006,51)$ \\
Runoff & $-0.406(0.003,51)$ & $0.64(0.0001,51)$ & $0.669(0.0001,51)$ & $0.674(0.0001,51)$ \\
\hline
\end{tabular}

a) $T_{4-9(\max )}$ indicates the mean maximum temperature of the current April to September; $P_{4-9}$ means the sum of precipitation from the current April to September; $P_{8-7}$ refers to annual precipitation from the previous August to the current July; and $P_{\text {ann }}$ represents calendar annual precipitation from the current January to December.

Yimin River, seasonal precipitation $\left(P_{4-9}\right)$, annual precipitation $\left(P_{8-7}\right)$ and calendar-year annual precipitation $\left(P_{\text {ann }}\right)$ are shown in Figure 5.

The effects of runoff on tree growth were similar to those found for precipitation. The runoff in a given year $t$ strongly influenced tree growth in years $t$ and $t+1$, the years immediately following the observation $[29,30]$. The correlations between the annual runoff of the Yimin River in year $t$ and HLBEstd, NGNEstd and RC in years $t$ and $t+1$ are given in Table 3. It is clear that the annual runoff of the Yimin River had a stronger relationship with RC than with the other variables considered, as shown by the high correlations of $0.662(P<0.0001)$ and $0.483(P<0.0001)$ for years $t$ and $t+1$, respectively. Therefore, the RC was used to reconstruct the annual runoff of the Yimin River for the Hulun Buir region beginning in 1868 .

\subsection{Annual runoff reconstruction}

Because annual runoff varies over a broad range (Figure 5), the water levels that influence ring widths if the amount of precipitation (and the resulting runoff) is high do not produce the same response rates that occur as a result of increases at lower levels of precipitation because the trees experience other growth restrictions, such as those resulting from the nutrient supply or internal biochemical limitations [31]. For this reason, the relationship between runoff and tree-ring data could be nonlinear. Plotting the estimated and recorded values or plotting one as a function of the other can reveal whether "a curvilinear model is more appropriate" [32]. Figure 6 shows the nonlinear relationship between the Yimin River annual runoff and the RC. The use of a logarithmic transformation of streamflow and tree-ring chronology has previously been examined [4]. The use of the $\log (\lg )$-transformed annual runoff of the Yimin River (1956-2003) significantly improved the relationship between the runoff and RC, i.e. the correlations of $\operatorname{lgRunoff}$ with $\mathrm{RC}$ in years $t$ and $t+1$ were $0.716(P<0.0001)$ and $0.502(P<0.0001)$, respectively. Therefore, the transfer function was designed as follows:

$$
\text { lgRunoff }=0.592 \mathrm{RC}_{t}+0.202 \mathrm{RC}_{t+1}+3.966,
$$

$\left(n=47, r=0.722, R^{2}=52.2 \%, R_{\text {adj }}^{2}=50 \%\right.$, standard error $=$ $0.147, F=24$, Durbin-Watson=1.375 and $P<0.0001$ ), where $\operatorname{lgRunoff}$ is the $\log 10$-transformed annual runoff of the Yimin River and $\mathrm{RC}_{t}$ and $\mathrm{RC}_{t+1}$ are the tree-ring width indices for the RC in years $t$ and $t+1$, respectively. The multiple correlation coefficient for eq. (1) was 0.722 , and the percentage of the variance explained was $52.2 \%$ (50\% after adjustment for the loss of degrees of freedom) for the calibration period 1956-2002.

The sign test (S1, S2), product mean $(t)$ and reduction of error (RE) were used to verify the transfer function [32]. The sign test (S1, S2) was based on the signs of the paired observed and estimated departures from the mean and the number of agreements or disagreements between the paired signs. Test S1 was performed for the first differences between the observation and the reconstruction, which reflected the high-frequency variations, whereas test S2 was a general sign test that measured the associations at all frequencies. At the 0.01 significance level, the model was satisfactory based on both test $\mathrm{S} 1(34,33 / 0.01)$ and test $\mathrm{S} 2$ (38, $33 / 0.01)$. The product mean $(t)$ and the reduction of error (RE) were 4.10 and 0.52 , respectively. These test statistics indicated that the annual runoff (lg-transformed) reconstruction captured the variances of both the observed and estimated data at both high and low frequencies.

In addition, the results obtained using the jackknife [33] and bootstrap [34] methods revealed that the values of $r, R^{2}$, $R_{\text {adj }}^{2}$, standard error, $F, P$ and the Durbin-Watson statistic were similar to the values found for the original data set (Table 4). The small differences associated with each statistic indicated that the calibration regression, eq. (1), was stable and reliable for the calibration period. The variations at both high and low frequencies for the reconstruction of the annual runoff (lg-transformed) of the Yimin River for 1868-2002 are shown in Figure 7.

\subsection{Extreme events}

Extreme values of high and low runoff could reflect dry or wet conditions. The mean value and standard deviation (SD) of the entire annual runoff (lg-transformed) reconstruction for 1868-2002 were 4.749 and 0.144 , respectively. We defined an extremely wet year as a year with a value $>$ mean +1 SD (=4.893) and an extremely dry year as a year with a runoff $<$ mean-1 SD (=4.606). Based on these criteria, 21 extremely dry years and 19 extremely wet years occurred during the reference period. These years represented 15.6 and $14.1 \%$ of the study period, respectively (Table 5). The four driest years were 1907 (<2 SD), 1987 (<2 SD), 1951 $(<2 \mathrm{SD})$ and $1906(<2 \mathrm{SD})$, and several missing rings 


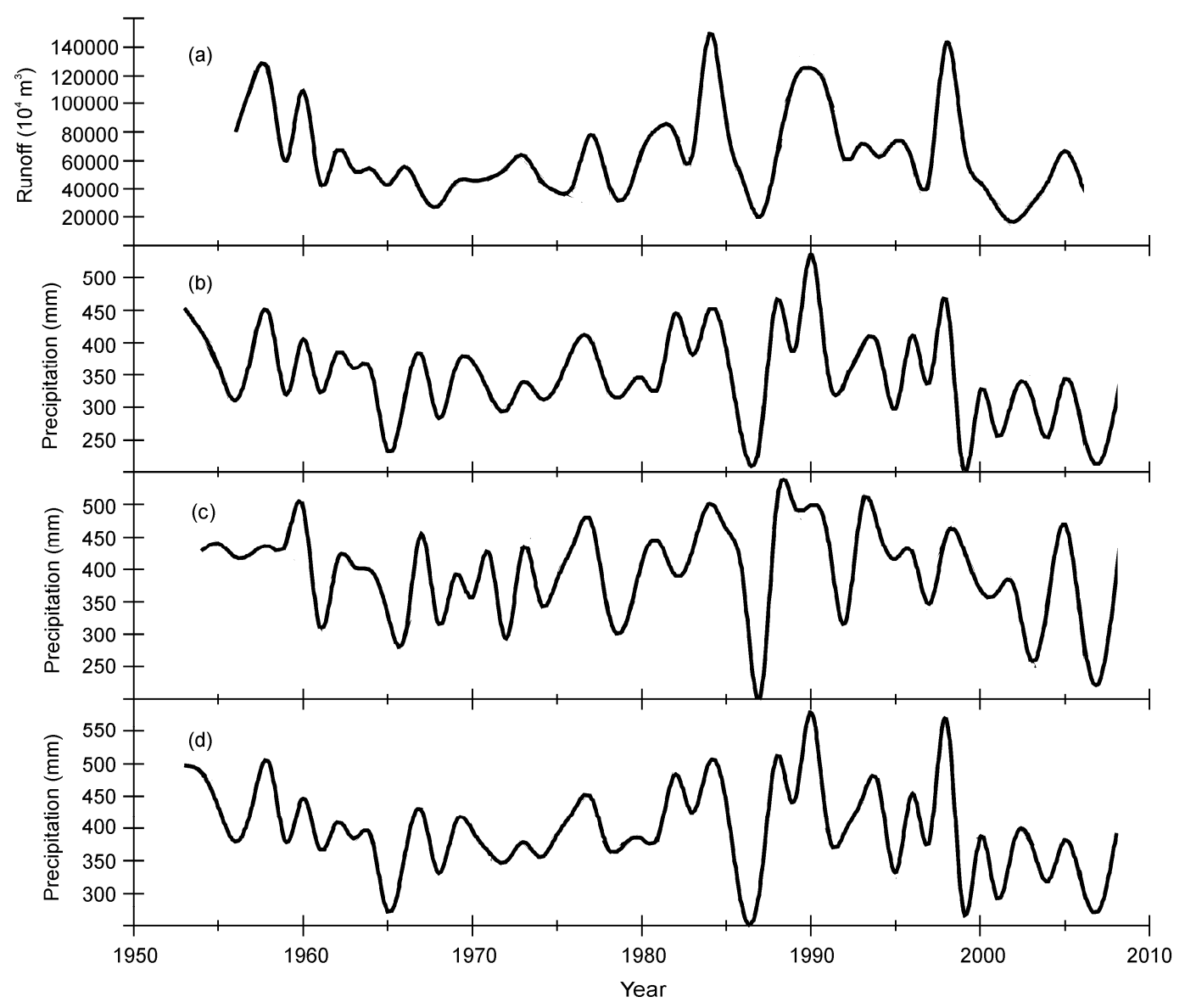

Figure 5 (a) Annual runoff of the Yimin River, (b) seasonal precipitation from the current April to September $\left(P_{4-9}\right)$, (c) annual precipitation from the previous August to the current July $\left(P_{8-7}\right)$ and (d) calendar-year annual precipitation from the current January to December $\left(P_{\text {ann }}\right)$.

Table 3 Correlations between tree-ring chronology (HLBEstd, NGNEstd and $\mathrm{RC}$ ) in years $t$ and $t+1$ and the mean annual runoff of the Yimin River in years $t$

\begin{tabular}{lcc}
\hline & $t$ & $t+1$ \\
\hline HLBEstd & $0.538^{* * *}$ & $0.469^{* * *}$ \\
NGNEstd & $0.628^{* * *}$ & $0.410^{* *}$ \\
RC & $0.662^{* * *}$ & $0.483^{* *}$ \\
\hline
\end{tabular}

appeared in 1907, 1987 and 1951. The three wettest years were 1868 (>2 SD), 1957 (>2 SD) and 1956 (>2 SD). Prolonged dry or wet periods generally have strong effects on local or regional social and agricultural activities. Among these extreme years, six severe dry events lasting two years or longer were found. These events occurred during 19501951, 1986-1987, 1905-1909, 1926-1928, 1968-1969 and 1919-1920. Four wetter events occurred during 1954-1959, 1932-1934, 1939-1940 and 1990-1991. It should be noted that the dry years reconstructed by tree-ring data are more reliable than the wet years because of the nonlinear influence of runoff on the radial growth of Pinus sylvestris var. mongolica. The reconstructions for several wet years appear to underestimate the amount of the actual annual runoff. For instance, the reconstructed values 4.99 (1984) and 4.914 (1990) are lower than the recorded values (lg-transformed) of 5.17 and 5.1, respectively. A similar phenomenon is shown by a tree-ring-based streamflow reconstruction for west-central Mongolia [31].

As stated above, runoff could represent regional hydroclimatic variations to a certain extent. Indeed, extremely dry/wet years (events) tended to occur over a large area within the Yimin River basin. For instance, the extremely dry years of 1907 (<2 SD), 1987 (<2 SD) and 1892 (<1 SD) were detected in the tree-ring-based annual rainfall reconstruction for Honghuaerji for 1806-2007 [16]. In particular, the extremely low runoff in 1987 (<2 SD) was recorded by many hydrological stations in the Hulun Biur region, including the Yiminmuchang, Bahou, Cuogang and Yakeshi stations [18]. The severe drought of 2001, occurring from the spring through the autumn (April, June-November), caused a series of severe problems in most of northeastern China, including our study area (http://www.weather.com.cn/ drought/ghsj/2001/05/443042.shtml). Large numbers of rivers and dams became dry, and grasslands degenerated as a result of the lower runoff levels and dry conditions.

The severe drought of 2001 produced a period of 130 


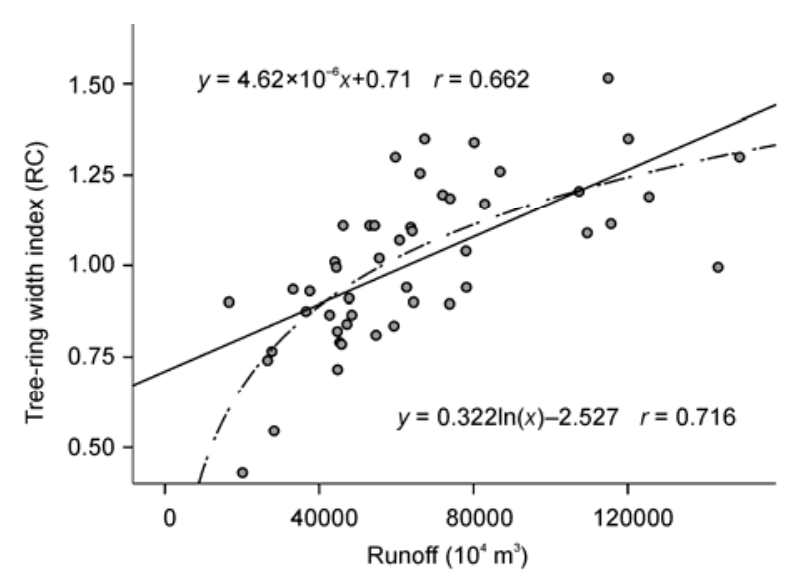

Figure 6 Scatterplot of the annual runoff of the Yimin River and RC from 1956-2003.

days with no streamflow in the Liao River. This dry interval was the longest on record at the Defudian hydrological station. According to the Haerbin gauge station, the lowest water level for the Songhuajiang River occurred on July 6, 2001 (http://www.weather.com.cn/drought/ghsj/2001/05/ 443042.shtml). In our reconstruction, the estimated value for 2001 accurately reflected the observed value. These values were 4.586 (<1 SD) and 4.43 (lg-transformed), respectively (Table 5).

The extremely low runoff period of 1926-1928 corresponded to the severe drought that occurred in the 1920s in an extensive area of northern China [35]. During that time, the records of the Shanxian hydrological station located in the middle section of the Yellow River showed an 11-year low runoff period from 1922 to 1932 [36]. In Inner Mongolia, the lowest water level of Daihai Lake over the past 200 years occurred in 1927-1929 [37]. The period of low flow observed in Hankou, Hubei Province, reflected the effects of the severe drought of the 1920s on the middle and upper reaches of the Yangtze River [38]. Previous tree-ring-based hydrological reconstructions, such as those conducted for the middle reaches of the Heihe River [9], the upper reaches of the Yellow River [6] and the Fenhe River [7], also captured the severe drought of the 1920s.

The dryness-wetness index (DWI) derived from the abundant climatic descriptions in Chinese historical documents is a very important source for studying past climatic change. The values of this index consist of five grades, namely very wet_1, wet_2, normal_3, dry_4 and very dry_5 [39]. The DWI values in the region near our study area were used to investigate the relationships between the extremely high runoff response and wet conditions. During 18681979 , eight of the eighteen extremely low-runoff years were categorized as DWI_4 or DWI_5, whereas six of the fifteen extremely high-runoff years corresponded to DWI_2 (Table 5). In particular, the severe drier/wetter events cited above (lasting two years or longer) accurately matched the DWI values.

The Yimin River basin is located at the edge of the East

Table 4 Jackknife and bootstrap calibration and verification statistics (1956-2002)

\begin{tabular}{|c|c|c|c|}
\hline \multirow{3}{*}{ Statistical item } & \multirow{3}{*}{ Calibration } & \multicolumn{2}{|c|}{ Verification } \\
\hline & & Jackknife & Bootstrap (80 iterations) \\
\hline & & Mean (range) & Mean (range) \\
\hline$r$ & 0.722 & $0.72(0.58-0.75)$ & $0.73(0.58-0.84)$ \\
\hline$R^{2}$ & 0.522 & $0.52(0.47-0.56)$ & $0.54(0.33-0.70)$ \\
\hline$R_{\text {adj }}^{2}$ & 0.5 & $0.50(0.44-0.54)$ & $0.52(0.30-0.69)$ \\
\hline Standard error of estimate & 0.147 & $0.148(0.135-0.149)$ & $0.142(0.111-0.185)$ \\
\hline$F$ & 24 & $23.49(18.85-27.12)$ & $26.99(11.01-50.53)$ \\
\hline$P$ & $<0.0001$ & $<0.0001$ & $<0.0001$ \\
\hline Durbin-Watson & 1.375 & $1.374(1.145-1.553)$ & $1.346(1.176-1.627)$ \\
\hline
\end{tabular}

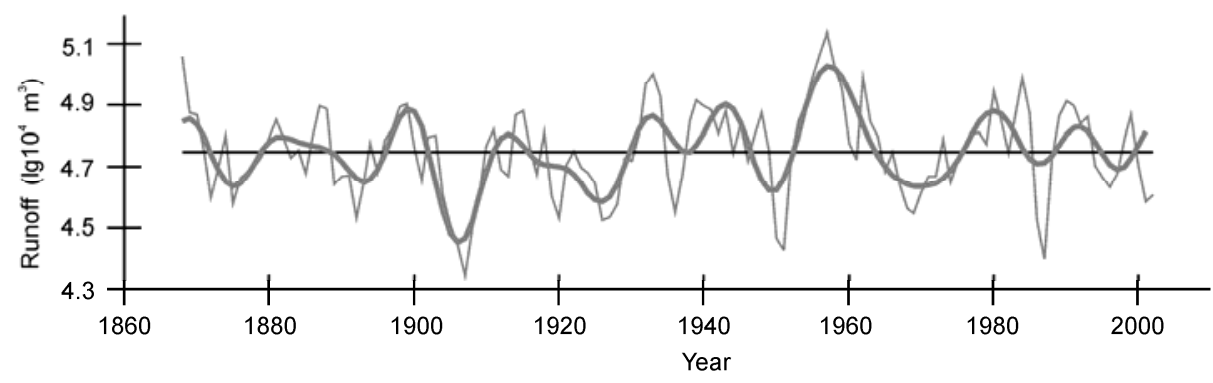

Figure 7 Annual runoff ( $\log 10$-transformed) reconstruction for the Yimin River (thin line) based on the 10-year low-pass filtered data (bold line) (1868-2002). 
Table 5 Rankings of years of extremely dry/wet reconstructed annual runoff (lg-transformed) of the Yimin River

\begin{tabular}{|c|c|c|c|c|c|c|c|c|}
\hline Rank & Dry_year & Value & Wet_year & Value & Dry_period & Value & Wet_period & Value \\
\hline 1 & 1907 & 4.347 & 1868 & 5.060 & $1950-1951$ & 4.449 & 1954-1959 & 5.012 \\
\hline 2 & 1987 & 4.402 & $1957^{\mathrm{c})}$ & 5.136 & $1986-1987$ & 4.462 & 1932-1934 & 4.966 \\
\hline 3 & $1951^{\mathrm{b})}$ & 4.431 & 1956 & 5.065 & 1905-1909 & 4.482 & 1939-1940 & 4.907 \\
\hline 4 & 1906 & 4.447 & 1958 & 5.028 & $1926-1928$ & 4.546 & 1990-1991 & 4.905 \\
\hline 5 & 1950 & 4.467 & 1933 & 5.002 & 1968-1969 & 4.556 & & \\
\hline 6 & 1908 & 4.504 & 1955 & 4.991 & 1919-1920 & 4.568 & & \\
\hline 7 & $1905^{\text {b) }}$ & 4.510 & 1984 & 4.990 & & & & \\
\hline 8 & 1986 & 4.521 & 1962 & 4.989 & & & & \\
\hline 9 & $1926^{\text {b) }}$ & 4.526 & $1932^{c)}$ & 4.967 & & & & \\
\hline 10 & 1892 & 4.531 & $1959^{\mathrm{c})}$ & 4.956 & & & & \\
\hline 11 & 1920 & 4.531 & 1980 & 4.945 & & & & \\
\hline 12 & 1927 & 4.535 & $1934^{c)}$ & 4.930 & & & & \\
\hline 13 & 1969 & 4.548 & 1939 & 4.917 & & & & \\
\hline 14 & $1936^{\mathrm{b})}$ & 4.551 & 1990 & 4.914 & & & & \\
\hline 15 & $1968^{b)}$ & 4.563 & 1899 & 4.903 & & & & \\
\hline 16 & 1928 & 4.578 & 1954 & 4.898 & & & & \\
\hline 17 & $1875^{\text {a) }}$ & 4.580 & $1940^{c)}$ & 4.897 & & & & \\
\hline 18 & 2001 & 4.586 & $1887^{\mathrm{c})}$ & 4.896 & & & & \\
\hline 19 & 1872 & 4.599 & 1991 & 4.896 & & & & \\
\hline 20 & $1909^{b)}$ & 4.603 & & & & & & \\
\hline 21 & $1919^{\text {a) }}$ & 4.605 & & & & & & \\
\hline
\end{tabular}

a) DWI_5; b) DWI_4; c) DWI_2.

Asian summer monsoon region. To a certain extent, the variations of the monsoon affect the region's precipitation and, thus, the changes in the level of runoff. This relationship was supported by the significant correlation between the reconstructed runoff and the East Asian monsoon index (EAMI) [40]. The correlation coefficient between the two series was $0.255(n=50, P=0.074,1951-2000)$. Moreover, the correlation coefficient after the application of an 11-year moving average to the two series was $0.432(P=0.005)$. These results suggest that during the latter half of the 20th century, the East Asian summer monsoon had an important influence on the Yimin River basin, i.e. the high EAMI reflects a higher level of precipitation and a resulting increase in the annual runoff, such as occurred during the longest extremely wet period from 1954 to 1959 . Likewise, a low EAMI would correspond to a low annual runoff. This relationship exists in the tree-ring-based precipitation reconstruction performed for the Ortindag Sand Land [41]. Of course, not all of the high EAMI values are associated with greater precipitation and high runoff, as in the case of the severe drought in the 1920s. Similarly, the extreme drought period during the 1920 s and 1930 s characterized by the DWI corresponds to the strong East Asian summer monsoon reflected by the stalagmite oxygen isotope series [42]. The possible reasons for these results are related to the variation in the East Asian summer monsoon on a decadal scale [40], the western Pacific subtropical high in summer, cold air masses from mid-latitudes and the circulation conditions over the western highlands [43]. Further studies are needed to resolve these questions.

\subsection{Regional comparison and teleconnections}

To examine the temporal and spatial variations in hydroclimatic conditions over a broad area, two other sources are available for comparison. One dataset, from a location approximately $1300 \mathrm{~km}$ west of our study area, is a reconstruction of the April-October streamflow of the Selenge River, based on tree rings in west-central Mongolia [31]. The other dataset, from a location approximately $700 \mathrm{~km}$ southwest of our study area, is a reconstruction of the August-July streamflow of the Kherlen River, based on tree rings in northeastern Mongolia [44]. Our annual runoff (lgtransformed) reconstruction showed significant correlations with the Selenge River reconstruction $(r=0.181, n=130$, $P=0.04)$, with the Kherlen River reconstruction $(r=0.162$, $n=129, P=0.066$ ) and with the principal component index of tree-ring chronologies (PC index) used for the Kherlen River streamflow reconstruction $(r=0.18, n=129, P=0.041)$. After applying an 11-year moving average, the correlation coefficients were $0.343(n=119, P<0.0001), 0.319(n=119$, $P<0.0001)$ and $0.476(n=119, P<0.0001)$, respectively. Compared with the strong correlations of these three series on a decadal scale, the relatively weak correlations on an interannual scale could be a result of the differences produced by the great spatial distances and the reconstructed 
climate window.

The peaks and valleys in the Z-scores of our Yimin River reconstruction, the PC index and the Selenge River reconstruction match each other very accurately, with different degrees of bidecadal-scale variations present since 1868 (Figure 8). On an interannual scale, extreme droughts lasting five years occurred in the reconstructions of the Yimin River, Kherlen River [44] and Selenge River [31] during 1905-1909, 1903-1907 and 1901-1905, respectively. The wetter periods occurring in the 1990s were 1990-1991, 1991-1995 and 1990-1994, respectively. The droughts in the 1900s, 1920s and 1970s; and the wetter intervals in the 1930 s-early 1940 s and late 1950 s-1960s were shown synchronously in these series. The common variations displayed in the hydroclimatic reconstructions based on the moisture-sensitive growth of trees in the three river basins considered in this analysis could reveal a possible linkage between a large part of the west central and northeastern Mongolia Plateau and large-scale climate forcing.

Power spectral analyses were performed on the filtered components of the annual runoff (lg-transformed) reconstruction of the Yimin River [32]. Significant cycles were found for periods of $20,14-16$ and 4-8 years. Similar cycles were detected in the reconstructions of the Kherlen River [44] and the Selenge River [31]. In addition, the influence of the Pacific Decadal Oscillation (PDO) $[45,46]$ and El Niño-Southern Oscillation (ENSO) [47] on the Selenge River basin, west central Mongolia, has been investigated [31]. A significant correlation was found between the result of the annual runoff reconstruction of the Yimin River and the PDO index. This analysis was based on treering data [48] $(r=-0.473, n=119, P<0.0001$, based on an 11-year moving average). The results of a wavelet analysis

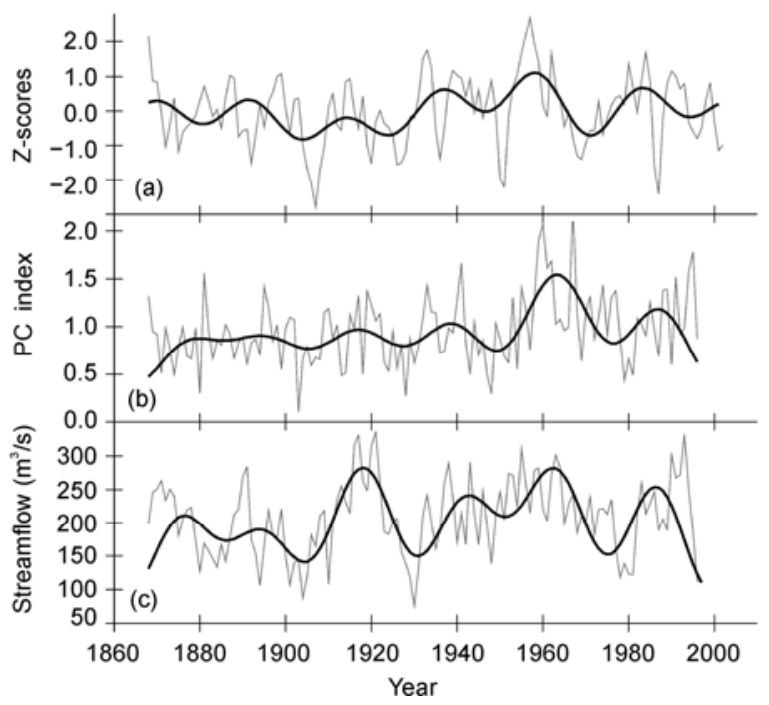

Figure 8 Comparison of (a) Z-scores of the Yimin River reconstruction, (b) the principal component index of tree-ring chronologies (PC index) used for the Kherlen River streamflow reconstruction [44] and (c) Selenge River reconstruction of the streamflow from the current April to October [31]. The bold line represents the 20-year low-pass-filter curve. included cycles similar to those found in the reconstruction performed by power spectral analyses. High power was found for the variability at the decadal scale, expressed in a range of 10-20 years, for the 1890s-1970s. This pattern was similar to that displayed by the PDO, with the principal "cool" regimes in 1890-1924 and 1947-1976 and the principal "warm" regimes in 1925-1946 and 1977-1990s [45,46] (Figure 9). The entire series showed detectable power within the ENSO range of variability [47], a span of 4 to 8 years, although this component of the power spectrum was relatively weak. The close relationships between the PDO and ENSO and Asian climatic conditions have been confirmed by many previous tree-ring studies [49,50].

The land-surface hydrological cycle shows intermittent multiannual patterns of variability, including 4-8-, 14-16and 20-25-year fluctuations. These patterns are consistent with known sea surface temperature and pressure fluctuations, such as the ENSO, PDO and North Atlantic Oscillation (NAO) [51]. Our annual runoff (lg-transformed) reconstruction also showed significant correlations with treering based reconstructions of North Atlantic sea surface temperature anomalies $(r=0.208, n=123, P=0.021)$ and the Atlantic Multidecadal Oscillation index $(r=0.31, n=118$, $P=0.001$ ) [52].

Because runoff can integrate hydrometeorological effects over a large region and amplify small fluctuations in rainfall, it is considered to be a sensitive parameter for the detection of the influence of the solar cycle on climate [53]. Significant correlations between the annual runoff (lg-transformed) reconstruction and the sunspot index $(r=0.429, n=47$ and $P=0.003$ for 1956-2002) (http://www.sidc.be/sunspot-data/, 'year(s)-of-data') indicate that solar activity plays an important role in the hydroclimatic variations of the Yimin

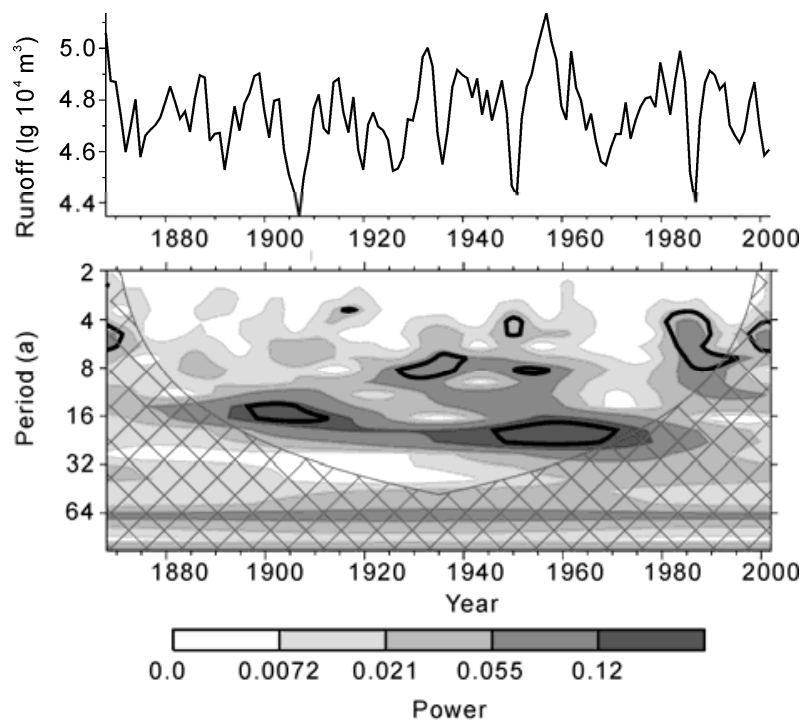

Figure 9 Wavelet plots for the annual runoff (lg-transformed) reconstruction of the Yimin River. Dark areas indicated by black contours (the 0.05 significance level, using a red-noise (autoregressive lag 1) background spectrum) represent regions of significant power at corresponding timescales [22]. 
River basin and its vicinity. The influence of solar activity on the regional hydroclimate has been investigated in the basins of the Kherlen River [44] and Selenge River [31].

The Mongolian Plateau, located in the center of Asia, is characterized by an extreme continental climate. During the winter, the plateau is particularly influenced by the Siberian High, which is closely related to the NAO and NPO (North Pacific Oscillation) [54-56]. Two additional global-scale climate systems play extremely important roles in the climate and environment of the Mongolian Plateau. The first system consists of the westerlies modulated by the NAO [57], and the second system is the East Asian summer monsoon, which is associated with the ENSO and the ITCZ (the Inter-tropical Convergence Zone) [58]. Trees growing on the Mongolian Plateau and in its vicinity are on the edge of these three large-scale climate systems. The trees in these locations record information on climatic variation influenced by large-scale climate forcing. Our annual runoff (lg-transformed) reconstruction for the Yimin River is a preliminary investigation of the relationship between the hydroclimatic variations occurring in the Yimin River basin and vicinity (the eastern margin of the Mongolian Plateau) and large-scale climate forcing. To better understand the physical mechanisms behind the relationships represented by teleconnections, more dendroclimatological studies should be conducted.

\section{Conclusions}

(1) Based on the moisture-sensitive tree-ring width chronology of Pinus sylvestris var. mongolica, a reconstruction of the annual runoff (lg-transformed) of the Yimin River was performed for 1868-2002. The model was stable and informative.

(2) Six severe drought events were identified over 21 extremely dry years: 1950-1951, 1986-1987, 1905-1909, 1926-1928, 1968-1969 and 1919-1920. Four wetter events were found over 19 extremely wet years: 1954-1959, 1932-1934, 1939-1940 and 1990-1991.

(3) Regional comparisons and periodicity analyses indicated that hydroclimatic variations of the west-central and northeastern Mongolian Plateau and vicinity could respond to large-scale climate forcing, such as that resulting from the PDO, the ENSO and sunspot activity.

The authors thank Director GE Yuxiang from HongHuaErJi, Forest National Nature Reserve, for supporting this work and Dr. DUAN Limin for annual runoff data. We also thank TIAN Hua, SU Bo, WANG Caiyong and SHEN Baofa for their great help during the filed work and data analysis. This work was supported by the National Natural Science Foundation of China (40890051 and 41171170), the Chinese Academy of Sciences (KZCX2-YW-Q1-01 and KZZD-EW-04), the One-hundred Talents Program of the Chinese Academy of Sciences, the State Key Laboratory of Loess and Quaternary Geology Foundation (SKLLQG1102) and Baoji University of Arts and Sciences (ZK11063).
1 Zou X K, Zhai P, Zhang Q. Variations in droughts over China: 19512003. Geophys Res Lett, 2005, 32: L04707

2 Zhang Q, Gao G. The spatial and temporal features of drought and flood disasters in the past 50 years and monitoring and warning services in China (in Chinese). Sci Technol Rev, 2004, 7: 21-24

3 Meko D M, Woodhouse C A, Morino K. Dendrochronology and links to streamflow. J Hydrol, 2012, 412-413: 200-209

4 Margolis E Q, Meko D M, Touchan R. A tree-ring reconstruction of streamflow in the Santa Fe River, New Mexico. J Hydrol, 2011, 397: 118-127

5 Meko D M, Therrell M D, Baisan C H, et al. Sacramento River flow reconstructed to AD 869 from tree rings. J Am Water Resour Assoc, 2001, 37: 1029-1040

6 Gou X H, Deng Y, Chen F H, et al. Tree ring based streamflow reconstruction for the Upper Yellow River over the past 1234 years. Chin Sci Bull, 2010, 55: 4179-4186

7 Sun J Y, Liu Y, Wang Y C, et al. Tree-ring based runoff reconstruction of the upper Fenhe River basin, North China, since 1799 AD. Quat Int, 2012, http://dx.doi.org/10.1016/j.quaint.2012.03.044

8 Woodhouse C A, Gray S T, Meko D M. Updated streamflow reconstructions for the Upper Colorado River basin. Water Resour Res, 2006, 42: W5415

9 Liu Y, Sun J, Song H, et al. Tree-ring hydrologic reconstructions for the Heihe River watershed, western China since AD1430. Water Res, 2010, 44: 2781-2792

10 Yuan Y J, Shao X M, Wei W S, et al. The potential to reconstruct Manasi River streamflow in the northern Tien Shan Mountains (NW China). Tree-Ring Res, 2007, 63: 81-93

11 He J C, Wang L L, Shao X M. The relationships between Scots pine tree ring indices and normalized difference vegetation index in Mohe, China (in Chinese). Quat Sci, 2005, 25: 252-257

12 Wang L L, Shao X M, Huang L, et al. Tree-ring characteristics of Larix Gmelinii and Pinus Sylvestris Var. Mongolia and their response to climate in Mohe, China (in Chinese). Acta Phytoecol Sin, 2005, 29: 380-385

13 Wang X C, Song L P, Zhang Y D. Climate-tree growth relationships of Pinus sylvestris var. mongolica in the northern Daxing'an Mountains, China (in Chinese). Chin J Plant Ecol, 2011, 35: 294-302

14 Zhang T W, Yuan Y J, Wei W S, et al. Tree-ring-based temperature reconstruction for the northern Greater Higgnan Mountains, China, since AD 1717. Int J Climatol, 2012, doi: 10.1002/joc.3433

15 Liu Y, Bao G, Song H M, et al. Precipitation reconstruction from Hailar pine (Pinus sylvestris var. mongolica) tree rings in the Hailar region, Inner Mongolia, China back to 1865 AD. Paleogeogr Paleoclimatol Paleoecol, 2009, 282: 81-87

16 Chen Z J, Zhang X L, Cui M X, et al. Tree-ring based precipitation reconstruction for the 332 forest-steppe ecotone in northern Inner Mongolia, China and its linkages to the Pacific Ocean variability. Glob Planet Change, 2012, 86-87: 45-56

17 Bao G, Liu Y, Linderholm H W. April-September mean maximum temperature inferred from Hailar pine (Pinus sylvestris var. mongolica) tree rings in the Hulun Buir region, Inner Mongolia, back to 1868 AD. Paleogeogr Paleoclimatol Paleoecol, 2012, 313-314: 162-172

18 Duan L M, Liu T X, Wang X X, et al. Development of a regional regression model for estimating annual runoff in the Hailar River Basin of China. J Water Resour Protec, 2010, 2: 934-943

19 Wang W H. Climate of Inner Mongolia (in Chinese). Beijing: China Meteorological Press, 1990. 1-273

20 Chinese Academy of Sciences (Compilatory Commission of Physical Geography of China). Physical Geography of China: Climate (in Chinese). Beijing: Science Press, 1984. 1-161

21 Wigley T, Briffa K R, Jones P D. On the average value of correlated time series, with applications in dendroclimatology and hydrometeorology. J Clim Appl Meteorol, 1984, 23: 201-213

22 Torrence C, Compo G P. A practical guide to wavelet analysis. Bull Am Meteorol Soc, 1998, 79: 61-78

23 Gao S Y, Lu R J, Qiang M R, et al. Reconstruction of precipitation in the last 140 years from tree ring at south margin of the Tengger Desert, China. Chin Sci Bull, 2005, 50: 2487-2492 
24 Liu Y, Sun J Y, Yang Y K, et al. Tree-ring precipitation records from Inner Mongolia, China, and the east Asian summer monsoon front variation since 1627 AD. Tree-Ring Res, 2007, 63: 3-14

25 Cai Q F, Liu Y, Bao G, et al. Tree-ring-based May-July mean temperature history for Lüliang Mountains, China, since 1836. Chin Sci Bull, 2010, 55: 3008-3014

26 Song H M, Liu Y. PDSI variations at Kongtong Mountain, China, inferred from a 283-year Pinus tabulaeformis ring width chronology. J Geophys Res, 2011, 116: D22111

27 Labat D. Wavelet analysis of the annual discharge records of the world's largest rivers. Adv Water Resour, 2008, 31: 109-117

28 Guo H D. The study of water resources distribution in Hailar River basin (in Chinese). Inner Mongolia Water Resour, 2008, 3: 71-73

29 Yuan Y J, Yu S L, Mu G J, et al. Reconstruction and analysis of the 355a runoff of the Manas River on the north slopes of Tianshan Mountains (in Chinese). J Glaciol Geocryol, 2005, 27: 411-417

30 Maxwell R S, Hessl A E, Cook E R, et al. A multispecies tree ring reconstruction of Potomac River streamflow (950-2001). Water Resour Res, 2011, 47: W05512

31 Davi N K, Jacoby G C, Curtis A E, et al. Extension of drought records for central Asia using tree rings: West-central Mongolia. J Clim, 2006, 19: 288-299

32 Fritts H C. Tree Rings and Climate. London: Academic Press, 1976

33 Mosteller F, Tukey J W. Data Analysis and Regression. Massachusetts: Addison- Wesley Publishing Company, 1977

34 Young G A. Bootstrap: More than a stab in the dark. Stat Sci, 1994, 9: 382-415

35 Liang E Y, Liu X H, Yuan Y J, et al. The 1920s drought recorded by tree rings and historical documents in the semi-arid and arid areas of northern China. Clim Change, 2006, 79: 403-432

36 Shi F C, Wang G A, Gao Z D, et al. Recurrence probability of 11year continuous low water period (1922-1932 AD) in the Yellow River (in Chinese). Adv Water Sci, 2: 258-263

37 Wang S M. The Daihai Lake: Environment Evolution and Climate Change. Hefei: University of Science \& Technology of China Press, 1990. 1-196

38 Qian W H, Lin X, Zhu Y F, et al. Climatic regime shift and decadal anomalous events in China. Clim Change, 2007, 84: 167-189

39 Academy of Meteorological Science. Yearly Charts of Dryness/ Wetness in China for the Last 500-year Period (in Chinese). Beijing: China Maps Press, 1981. 1-332

40 Guo Q Y, Cai J N, Shao X M, et al. Studies on the variations of East Asian summer monsoon during A D 1873-2000 (in Chinese). Chin J Atmos Sci, 2004, 28: 206-215

41 Liang E Y, Dieter E, Liu H Y. Climate-growth relationships of relict
Pinus tabulaeformis at the northern limit of its natural distribution in northern China. J Veget Sci, 2008, 19: 393-406

42 Yang B, Tan M. Variability of the East Asian summer monsoon and its relationship with regional temperature and moisture change during the last millennium (in Chinese). Quat Sci, 2009, 29: 880-887

43 Zhao Z G. Drought and Flood in Summer and Its Environmental Field (in Chinese). Beijing: China Meteorological Press, 1999. 1-297

44 Pederson N, Jacoby G C, D'Arrigo R, et al. Hydrometeorological reconstructions for northeastern Mongolia derived from tree rings: AD 1651-1995. J Clim, 2000, 14: 872-881

45 Mantua N J, Hare S R. The Pacific decadal oscillation. J Oceanogr, 2002, 58: 35-44

46 Minobe S. Resonance in bidecadal and pentadecadal climate oscillations over the North Pacific: Role in climatic regime shifts. Geophys Res Lett, 1999, 26: 855-858

47 Allan R, Lindesay J, Parker D. El Niño-Southern Oscillation and Climatic Variability. Melbourne: CSIRO Publishing, 1996

48 MacDonald G M, Case R A. Variations in the Pacific Decadal Oscillation over the past millennium. Geophys Res Lett, 2005, 32: L08703

49 D'Arrigo R, Wilson R. On the Asian expression of the PDO. Int J Climatol, 2006, 26: 1607-1617

50 Li Z S, Zhang Q B, Ma K P. Tree-ring reconstruction of summer temperature for AD 1475-2003 in the central Hengduan Mountains, Northwestern Yunnan, China. Clim Change, 2011, doi: 10.1007/ s10584-011-0111-z

51 Labat D. Oscillations in land surface hydrological cycle. Earth Planet Sci Lett, 2006, 242: 143-154

52 Gray S T, Graumlich L J, Betancourt J L, et al. A tree-ring based reconstruction of the Atlantic Multidecadal Oscillation since 1567 AD. Geophys Res Lett, 2004, 31: L12205

53 Hoyt D V, Schatten K H. Rainfall. In: Hoyt D V, Schatten K H, eds. The Role of the Sun in Climate Change. Oxford: Oxford University Press, 1997. 125-142

54 Gong D Y, Wang S W, Zhu J H. East Asian winter monsoon and arctic oscillation. Geophys Res Lett, 2001, 28: 2073-2076

55 Hoerling M P, Hurrell J W, Xu T. Tropical origins for recent North Atlantic climate change. Science, 2001, 292: 90-92

56 Kerr R A. A new force in high-latitude climate. Science, 1999, 284 : 241-242

57 Visbeck M. The ocean's role in Atlantic climate variability. Science, 2002, 297: 2223-2224

58 Tudhope A W, Chilcott C P, McCulloch M T, et al. Variability in the El Niño-Southern oscillation through a glacial-interglacial cycle. Science, 2001, 291: 1511-1517

Open Access This article is distributed under the terms of the Creative Commons Attribution License which permits any use, distribution, and reproduction in any medium, provided the original author(s) and source are credited. 